\title{
Deletion of the Sequence Encoding the Tail Domain of the Bone Morphogenetic Protein type 2 Receptor Reveals a Bone Morphogenetic Protein 7-Specific Gain of Function
}

\author{
Patricio A. Leyton ${ }^{1 *} \odot$, Hideyuki Beppu ${ }^{1,2 \odot}$, Alexandra Pappas ${ }^{1}$, Trejeeve M. Martyn ${ }^{1}$, Matthias Derwall ${ }^{1,3}$, \\ David M. Baron ${ }^{1,4}$, Rita Galdos ${ }^{5}$, Donald B. Bloch ${ }^{1,5}$, Kenneth D. Bloch ${ }^{1,6}$
}

1 Anesthesia Center for Critical Care Research, Department of Anesthesia, Critical Care and Pain Medicine, Massachusetts General Hospital and Harvard Medical School, Boston, Massachusetts, United States of America, 2 Department of Clinical Laboratory and Molecular Pathology, Graduate School of Medicine and Pharmaceutical Science, University of Toyama, Toyama, Toyama Prefecture, Japan, 3 Department of Anesthesiology, Uniklinik Aachen, RWTH Aachen University, Aachen, North Rhine-Westphalia, Germany, 4 Department of Anesthesia, General Intensive Care, and Pain Management, Medical University of Vienna, Vienna, Austria, 5 Center for Immunology and Inflammatory Diseases, Department of Medicine, Massachusetts General Hospital and Harvard Medical School, Boston, Massachusetts, United States of America, 6 Cardiovascular Research Center, Cardiology Division of the Department of Medicine, Massachusetts General Hospital and Harvard Medical School, Boston, Massachusetts, United States of America

\begin{abstract}
The bone morphogenetic protein (BMP) type II receptor (BMPR2) has a long cytoplasmic tail domain whose function is incompletely elucidated. Mutations in the tail domain of BMPR2 are found in familial cases of pulmonary arterial hypertension. To investigate the role of the tail domain of BMPR2 in BMP signaling, we generated a mouse carrying a Bmpr2 allele encoding a non-sense mediated decay-resistant mutant receptor lacking the tail domain of Bmpr2. We found that homozygous mutant mice died during gastrulation, whereas heterozygous mice grew normally without developing pulmonary arterial hypertension. Using pulmonary artery smooth muscle cells (PaSMC) from heterozygous mice, we determined that the mutant receptor was expressed and retained its ability to transduce BMP signaling. Heterozygous PaSMCs exhibited a BMP7-specific gain of function, which was transduced via the mutant receptor. Using siRNA knockdown and cells from conditional knockout mice to selectively deplete BMP receptors, we observed that the tail domain of Bmpr2 inhibits Alk2-mediated BMP7 signaling. These findings suggest that the tail domain of Bmpr2 is essential for normal embryogenesis and inhibits Alk2-mediated BMP7 signaling in PaSMCs.
\end{abstract}

Citation: Leyton PA, Beppu H, Pappas A, Martyn TM, Derwall M, et al. (2013) Deletion of the Sequence Encoding the Tail Domain of the Bone Morphogenetic Protein type 2 Receptor Reveals a Bone Morphogenetic Protein 7-Specific Gain of Function. PLoS ONE 8(10): e76947. doi:10.1371/ journal.pone.0076947

Editor: You-Yang Zhao, University of Illinois College of Medicine, United States of America

Received June 5, 2013; Accepted August 27, 2013; Published October 8, 2013

Copyright: @ 2013 Leyton et al. This is an open-access article distributed under the terms of the Creative Commons Attribution License, which permits unrestricted use, distribution, and reproduction in any medium, provided the original author and source are credited.

Funding: Funding came from National Institutes of Health Heart, Lung and Blood Institute HL074352, http://www.nhlbi.nih.gov, DE-1685-1/1, Deutsche Forschungsgemeinschaft, http://www.dfg.de/en/. The funders had no role in study design, data collection and analysis, decisio to publish, or preparation of the manuscript.

Competing interests: The authors have declared that no competing interest exist.

*E-mail: pleyton@partners.org

๑ These authors contributed equally to this work.

\section{Introduction}

Bone morphogenetic proteins (BMPs) were initially identified as signaling factors involved in the formation of bone and cartilage. BMPs are now known to participate in a broad spectrum of biological activities during embryogenesis and organogenesis, as well as in the homeostasis of mature organs $[1,2]$. BMPs are members of the transforming growth factor beta family. BMPs bind to heterotetrameric receptor complexes formed by BMP type 2 and BMP type 1 serine-threonine kinases. Upon assembly of the BMP receptor complex by a BMP ligand, the constitutively active type 2 receptor phosphorylates the type 1 receptor, which in turn activates cytoplasmic BMP-responsive Smad signaling moleculesSmads 1, 5, and 8. Phosphorylated BMP-responsive Smads interact with Smad4 and translocate into the nucleus, where they modulate the transcription of BMP-responsive genes, such as Id1 and Smad6 [2-4].

BMP receptors include four type 1 (Alk1, Alk2, Alk3 and Alk6) and three type 2 kinases (Bmpr2, Acvr2a and Acvr2b) [2]. The expression of these receptors differs depending on the cell type or tissue. For example, mouse pulmonary artery smooth muscle cells (PaSMCs) express Bmpr2 and Acvr2a with lower amounts of Acvr2b; Alk2 and Alk3 are the predominant BMP type 1 receptors expressed in PaSMCs [5]. All BMP receptors have a similar structure including an extracellular ligand- 
binding domain, a transmembrane domain, and a cytoplasmic serine-threonine kinase domain. Unlike other BMP receptors, the predominantly expressed form of Bmpr2 (Bmpr2-WT) contains a long cytoplasmic tail domain (Bmpr2-TD) encoded by $B m p r 2$ exons 12 and 13 [6,7]. In a small fraction of Bmpr2 transcripts, exon 12 is alternatively spliced, resulting in a shortform variant of the receptor [7]. Although the Bmpr2-TD has been reported to interact with several proteins that can modulate BMP signaling $[8,9]$, the functional role of the Bmpr2-TD remains to be fully defined.

BMPR2 is implicated in the development of pulmonary arterial hypertension (PAH) $[10,11]$. $\mathrm{PAH}$ is a disease of the pulmonary circulation characterized by neointimal formation, obstruction of vessels, plexiform lesions, and pruning of the small pulmonary arteries [12]. Heterozygous BMPR2 mutations have been reported in approximately $75 \%$ of patients with hereditary $\mathrm{PAH}$ and in $25 \%$ of idiopathic cases [13]. Seventy percent of $B M P R 2$ mutations introduce a premature termination codon [14]. BMPR2 transcripts containing premature termination codons are subject to nonsense-mediated decay (NMD), an RNA surveillance mechanism that degrades aberrant mRNAs $[15,16]$. BMPR2 transcripts that undergo NMD lead to functional haploinsufficiency. However, some types of mutant transcripts can escape NMD, and the translated mutant receptor may exhibit a more deleterious phenotype by acting, for example, in a dominant-negative manner. It has been reported that $\mathrm{PAH}$ has an earlier onset and a worse prognosis in patients that carry NMD-resistant BMPR2 mutations than in patients who carry NMD-sensitive BMPR2 mutations [17].

In previous studies, we examined the impact of Bmpr2 haploinsufficiency on BMP signaling in PaSMCs isolated from genetically modified mice. We observed that PaSMCs isolated from heterozygous mice carrying a Bmpr2 mutant allele lacking exons 4 and $5\left(\mathrm{Bmpr}^{+/}\right)$were less responsive to BMP4 and BMP7 than were PaSMCs isolated from WT mice $[5,18]$. We also investigated the impact of complete loss of Bmpr2 using PaSMCs from mice harboring mutant $B m p r 2$ alleles in which exon 4 and 5 were flanked with loxP sequences (Bmpr2 floxflox $)$ [5]. When both Bmpr2 alleles were disrupted $\left(B m p r 2^{\text {del/de/ }}\right)$ in PaSMCs, BMP4 signaling was diminished, whereas BMP7 signaling was unexpectedly increased. We found that Acvr2a, but not Acvr2b, compensated for the absence of Bmpr2.

To investigate the role of the tail domain of Bmpr2 and model the impact of an NMD-resistant Bmpr2 mutation, we generated mice that carry a mutant Bmpr2 allele $\left(B m p r 2^{\Delta t d}\right)$, which encodes a receptor lacking the tail domain of Bmpr2 (Bmpr2- $\triangle T$ TD). We isolated PaSMCs from mice carrying the $B m p r 2^{\Delta t d}$ allele to characterize the role of Bmpr2-TD in BMP signaling.

\section{Results}

\section{Generation and phenotype of mutant mice harboring the Bmpr2 ${ }^{\Delta t d}$ allele}

The mutant $B m p r 2^{\Delta t d}$ allele was generated by inserting a cassette encoding the enhanced green fluorescent protein (Egfp) and a stop codon in frame after exon 11. The strategy for generating mice carrying the mutant $B m p r 2^{\Delta t d}$ allele is described in Methods and Figure S1. We observed that $B m p r 2^{\Delta t d / \Delta t d}$ mice died early in embryogenesis (embryonic day (E) 7.5 to 8.5), revealing a previously unknown role for the Bmpr2-TD in embryogenesis. In contrast, $\mathrm{Bmpr}^{\Delta t d /+}$ mice grow normally and have a lifespan similar to that of their WT littermates. Right ventricular systolic pressure and mean arterial pressure did not differ between $B m p r 2^{\Delta t d /+}$ and WT mice at 6 to 8 months of age (Figure S2). These findings suggest that $B m p r 2^{\Delta t d /+}$ mice do not spontaneously develop PAH.

\section{Expression of Bmpr2- $\Delta$ TD in PaSMCs}

To begin to understand the impact of the Bmpr2 $2^{\Delta t d}$ allele on BMP signaling, we sought to determine whether the mutant Bmpr2 gene is expressed. Bmpr2 ${ }^{+}$and Bmpr2 $2^{\Delta t d}$ mRNA and protein levels were measured in PaSMCs using quantitative real-time PCR (qPCR) and immunoblot techniques, respectively. Total Bmpr2 mRNA levels did not differ between WT and Bmpr2 ${ }^{\Delta t d /+}$ PaSMCs, when determined using oligonucleotides spanning the Bmpr2 exon 6-7 junction (Figure 1A). Bmpr2 ${ }^{+}$mRNA levels in Bmpr2 ${ }^{\Delta t d /+}$ PaSMCs were half of those observed in WT cells when measured using oligonucleotides spanning the exon 12-13 junction. Immunoblot analysis showed that levels of Bmpr2-WT were less in Bmpr2 $2^{\Delta t d /+}$ PaSMCs than in WT PaSMCs. The protein expressed by the mutant allele, Bmpr2- $\Delta T D$, in $B m p r 2^{\Delta t d /+}$ cells was smaller ( 100 kDa) than Bmpr2-WT (Figure 1B). These results show that the Bmpr2 $2^{\Delta t d}$ allele is transcribed, Bmpr $2^{\Delta t d}$ transcripts are resistant to NMD, and Bmpr2- $\triangle T$ TD protein is expressed in PaSMCs.

To determine whether Bmpr2- $\Delta$ TD can localize to the cell membrane, PaSMCs were transfected with a plasmid directing the expression of $B m p r 2^{\Delta t d}$, following by immunostaining with an antibody directed against GFP. Confocal microscopy revealed that the mutant receptor localized to the cell membrane (Figure $1 \mathrm{C}$ ). This finding suggests that the Bmpr2-TD is not required for intracellular trafficking of Bmpr2-WT to the cell membrane.

\section{Bmpr2 ${ }^{\Delta t d /+}$ PaSMCs exhibit a BMP ligand-specific gain of function}

The observation that Bmpr2- $\Delta T D$ localizes to the cell membrane suggested that the mutant receptor could participate in BMP signaling. To investigate the impact of the Bmpr2-TD on BMP signaling, we compared PaSMCs from WT and $B m p r 2^{\Delta t d /+}$ mice. Incubation with BMP4 induced the phosphorylation of Smad1/5/8 and expression of the Id 1 gene similarly in WT and Bmpr2 $2^{\Delta t d /+}$ PaSMCs (Figure 2A and B). In both WT and Bmpr2 $2^{\Delta t d /+}$ PaSMC, BMP4 induction of $/ d 1$ gene expression peaked at 4 hours (Figure 2A) and persisted for up to 24 hours (Figure S3). In contrast, incubation with BMP7 for 1.5 and 4 hours led to a greater induction of Smad1/5/8 phosphorylation and $I d 1$ and Smad6 gene expression in $B m p r 2^{\Delta t d /+}$ PaSMCs than in WT cells (Figure 2B and C). After 8 hours of exposure to BMP7, levels of Id1 mRNA returned to baseline (Figure 2B). These findings suggest that loss of one copy of the Bmpr2-TD leads to a BMP ligand-specific gain of function. 
A

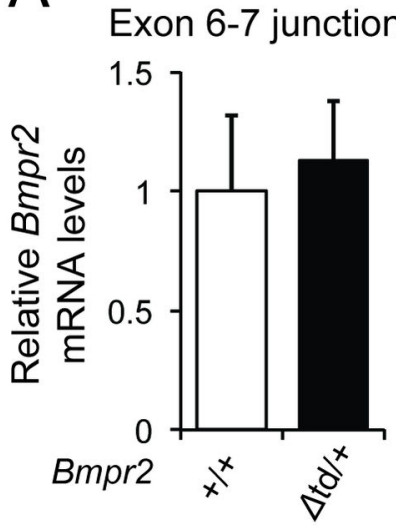

Exon 12-13 junction

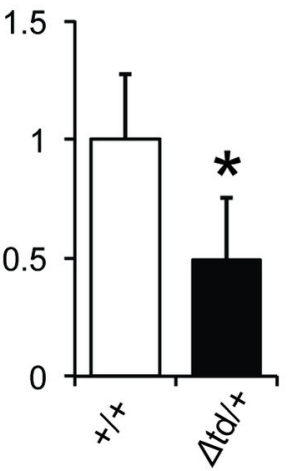

B

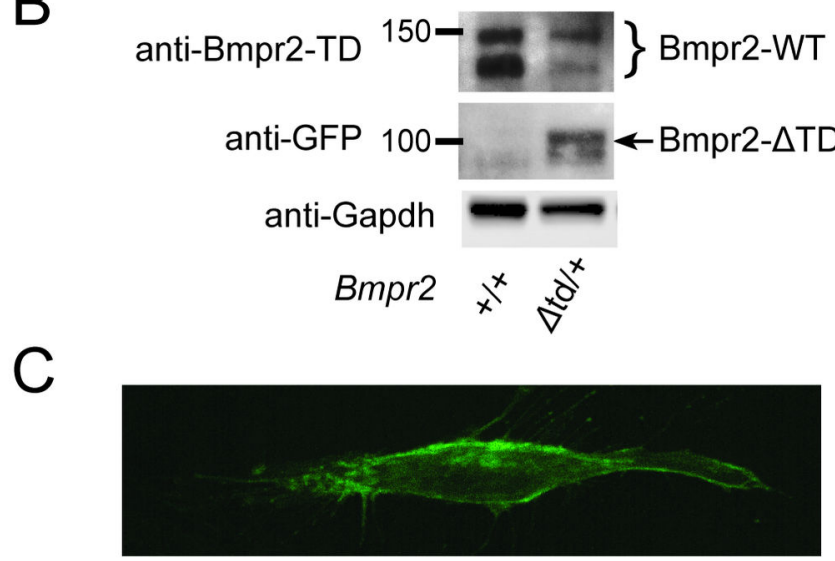

Figure 1. Bmpr2 expression in PaSMCs obtained from WT or Bmpr2 ${ }^{\Delta t d /+}$ mice. (A) Levels of Bmpr2 mRNA were measured in WT $\left(\mathrm{Bmpr}^{+/+}\right)$or Bmpr2 ${ }^{\Delta t d /+}$ PaSMCs by qPCR using hydrolysis probes for Bmpr2 exon junctions 6-7 and 12-13. Bmpr2 mRNA levels were normalized to Gapdh and expressed as the fold-change relative to $B m p r 2^{+/+} \mathrm{PaSMCs}$. ${ }^{*} \mathrm{P}<0.01$ compared to $\mathrm{Bmpr} 2^{+/+}$ PaSMCs. (B) Immunoblots prepared from lysates of $B m p r 2^{+/+}$and Bmpr2 ${ }^{\Delta t d /+}$ PaSMCs were incubated with an antibody directed against the tail domain of Bmpr2 to detect Bmpr2-WT or with an anti-GFP antibody to detect Bmpr2- $\Delta$ TD. Immunoblots were subsequently incubated with an antibody directed against Gapdh as a control for protein loading. (C) Confocal microscopy image of a PaSMC transiently transfected with a plasmid directing expression of $B m p r 2^{\Delta t d}$ and reacted with an anti-GFP antibody showing localization of Bmpr2- $\triangle \mathrm{TD}$ at the cell membrane.

doi: 10.1371/journal.pone.0076947.g001

\section{Bmpr2- $\triangle$ TD contributes to the increased responsiveness of Bmpr2 ${ }^{\Delta t d /+}$ PaSMCs to BMP7}

To investigate whether the enhanced responsiveness of Bmpr2 ${ }^{\Delta t d /+}$ PaSMCs to BMP7 depends on the presence of Bmpr2- $\Delta T D, B m p r 2^{\Delta t d /+}$ PaSMCs were treated with small interfering RNAs (siRNAs) to silence $B m p r 2^{+}$mRNA (targeting Bmpr2 exon 12; siBmpr2-ex12) or Bmpr2 $2^{\Delta t d}$ mRNA (targeting Egfp; siEgfp). The ability of BMP7 to induce Id1 and Smad6 gene expression was retained in Bmpr $2^{\Delta t d /+}$ PaSMCs treated with siBmpr2-ex12, but decreased in cells treated siEgfp (Figure 3A). These data suggest that the enhanced BMP7 signaling seen in $B m p r 2^{\Delta t d /+} \mathrm{PaSMC}$ s requires $\mathrm{Bmpr} 2-\triangle \mathrm{TD}$.

To confirm that the increased BMP7 signaling seen in $B m p r 2^{\Delta t d /+}$ cells does not require expression of the wild-type allele, we infected PaSMCs from Bmpr2 ${ }^{\Delta t d / f l o x}$ mice with an adenovirus specifying Cre recombinase (Ad-Cre) to delete the Bmpr2flox allele (Bmpr2 $2^{\Delta t d / d e l}$ PaSMCs). Bmpr2 $2^{\Delta t d / f l o x}$ cells infected with an adenovirus specifying red fluorescent protein (Ad-RFP) were used as control. Bmpr2 ${ }^{\Delta t d / d e l}$ PaSMCs did not express detectable Bmpr2-WT protein (Figure S4). Incubation with BMP4 led to a similar induction of Smad1/5/8 phosphorylation (Figure 3B) and Id1 and Smad6 gene expression (Figure 3C) in Bmpr2 $2^{\Delta t d / f l o x}$ and Bmpr2 ${ }^{\Delta t d / d e l}$ PaSMCs. In contrast, incubation with BMP7 led to a greater increase in the phosphorylation of Smad1/5/8 and in $I d 1$ and Smad6 gene expression in $B m p r 2^{\Delta t d / d e l}$ than in Bmpr2 $2^{\Delta t d / f l o x}$ PaSMCs. These results provide additional support for the concept that the presence of Bmpr2-WT is not required for Bmpr2 ${ }^{\Delta t d / f l o x}$ PaSMCs to signal in response to BMP7. Moreover, the presence of the Bmpr2 ${ }^{+}$ allele appears to inhibit signaling via Bmpr2- $\Delta T D$.
Since Acvr2a, but not Acvr2b, can compensate for the absence of Bmpr2 in Bmpr2 ${ }^{\text {del/del }}$ PaSMCs [5], we considered the possibility that Acvr2a was responsible for BMP signaling in $B m p r 2^{\Delta t d /+}$ or Bmpr2 $2^{\Delta t d / d e l}$ PaSMCs. Silencing Acvr2a mRNA modestly increased the ability of BMP4 to induce Id1 gene expression in Bmpr2 ${ }^{\Delta t d /+}$ PaSMCs, as well as the ability of BMP4 to induce Smad6 gene expression in Bmpr2 $2^{\Delta t d /+}$ and $B m p r 2^{\Delta t d / d e l}$ PaSMCs (Figure 4). These findings show that Acvr2a is not required for BMP4 signaling in Bmpr2 ${ }^{\Delta t d /+}$ or Bmpr2 ${ }^{\Delta t d / d e l}$ PaSMCs. In contrast, silencing Acvr2a mRNA modestly decreased the ability of BMP7 to induce Id1 and Smad6 gene expressions in Bmpr $2^{\Delta t d / d e l}$ PaSMCs (Figure 4), as well as decreasing the ability of BMP7 to induce Id1 gene expression in Bmpr $2^{\Delta t d /+}$ PaSMCs. These findings show that Bmpr2- $\triangle T D$ and, to a lesser extent, Acvr2a can transduce BMP7 signaling in PaSMCs harboring the Bmpr2 ${ }^{\Delta t d}$ allele.

\section{Alk2 is required for the response of $B m p r 2^{\Delta t d /+}$ PaSMCs to BMP7}

Based on our previous findings in Bmpr2 $2^{\text {del/del }}$ PaSMCs [5] and the high affinity of BMP7 for Alk2 [19,20], we hypothesized that the response to BMP7 would be less in Bmpr2 $2^{\Delta t d /+}$ cells deficient in Alk2 than in Bmpr2 $2^{\Delta t d /+}$ cells that express Alk2. To test this hypothesis, we generated $B m p r 2^{\Delta t d /+}$ mice carrying Alk2, Alk3, or both alleles flanked by loxP sequences. PaSMCs from these mice were infected with Ad-Cre to delete alleles flanked by loxP sequences or Ad-RFP as a control. Incubation with BMP4 induced $I d 1$ and Smad6 gene expression similarly in Bmpr2 $2^{\Delta t d /+} ; A l k 2^{f l o x / f l o x}$ and Bmpr2 $2^{\Delta t d /+} ; A l k 2^{d e l / d e l}$ PaSMCs (Figure 5A). In contrast, incubation with BMP4 induced Id1 and Smad6 gene expression less in $B m p r 2^{\Delta t d /+} ; A l k 3^{\text {del/del }}$ than in 
A

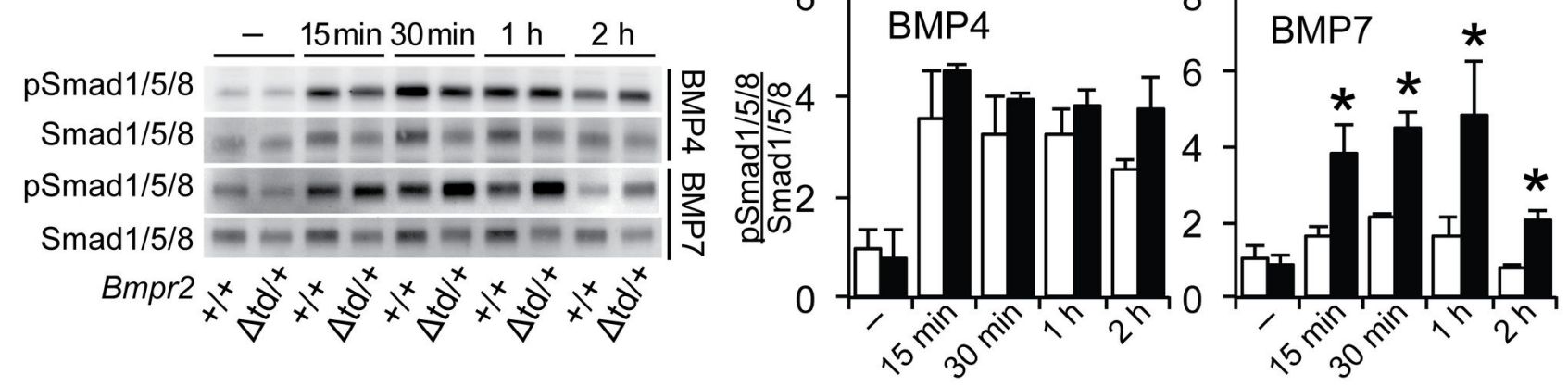

$\mathrm{B}$

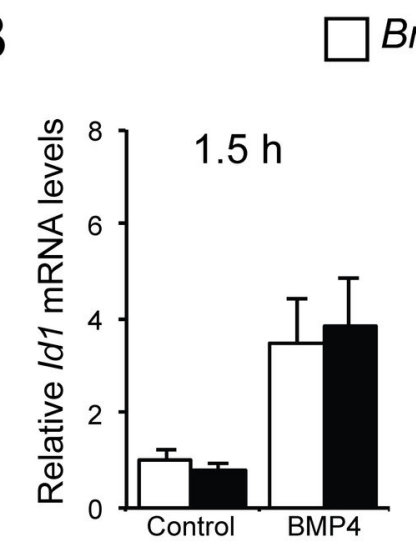

Bmpr2+/+

$B m p r 2 \Delta t d /+$

C
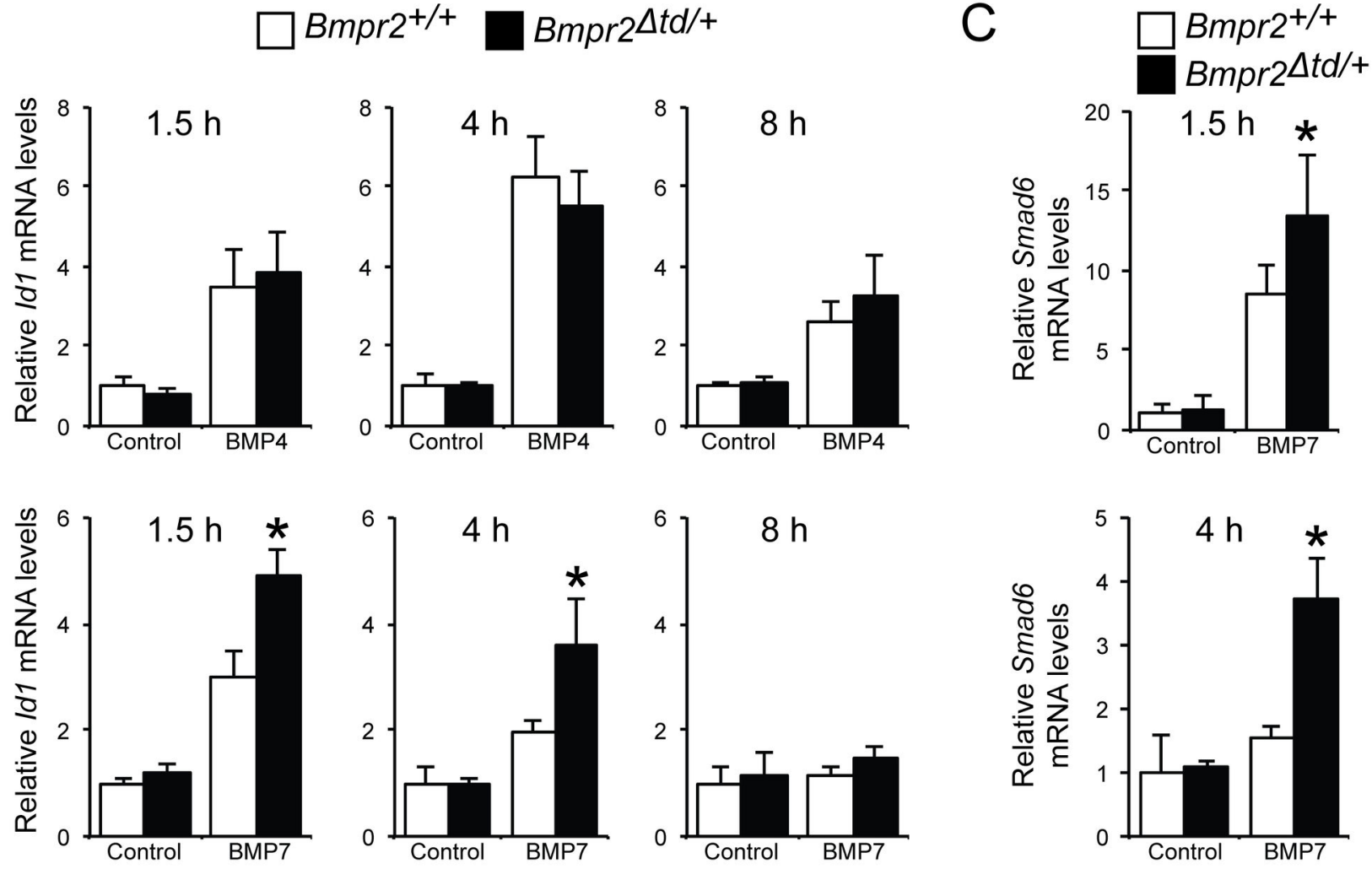

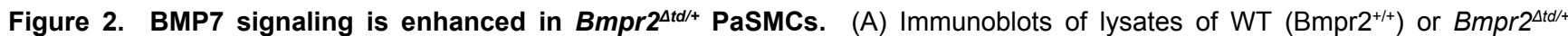
PaSMCs treated with BMP4 or BMP7 $(10 \mathrm{ng} / \mathrm{ml})$ for various times were reacted with antibodies directed against phosphorylated and total Smad1/5/8. Quantification of the ratio of phosphorylated Smad1/5/8 to total Smad1/5/8 (analysis of 3 independent experiments)

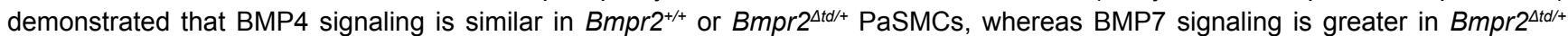
PaSMCs. ${ }^{*}<0.05$ compared to Bmpr2 ${ }^{+/+}$PaSMC group treated with BMP7. Id1 (B) and Smad6 (C) mRNA levels were measured by qPCR in $\mathrm{Bmpr}^{+/+}$or Bmpr2 ${ }^{\Delta t / /+}$ PaSMCs treated with BMP4 or BMP7 (10 ng/ml) for various times. Id1 and Smad6 gene expression

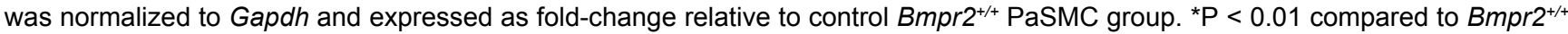
PaSMC group treated with BMP7.

doi: 10.1371/journal.pone.0076947.g002

$B m p r 2^{\Delta t d /+} ; A / k 3^{\text {floxflox }}$ PaSMCs (Figure 5B). The ability of BMP7 to induce Id1 and Smad6 gene expression was markedly less in Bmpr2 $2^{\Delta t d /+} ; A / k 2^{\text {del/del }}$ than in Bmpr2 $2^{\Delta t d /+} ; A l k 2^{\text {flox/lox }}$ PaSMCs and was similar in Bmpr $2^{\Delta t d /+} ; A / k 3^{\text {floxflox }}$ and $B m p r 2^{\Delta t d /+} ; A l k 3^{\text {del/del }}$ PaSMCs (Figure 5). These results suggest that the enhanced responsiveness of $B m p r 2^{\Delta t d /+}$ PaSMCs to BMP7 requires the presence of Alk2. To corroborate these results, we examined the contribution of Bmpr2- $\triangle$ TD or Bmpr2-WT to mediate BMP7 signaling in PaSMCs predominantly expressing Alk2 (i.e. in Alk3-deficient PaSMCs). Silencing of $\mathrm{Bmpr}^{+}$transcripts in Bmpr2 ${ }^{\Delta t d /+} ;$ Alk $3^{\text {del/del }}$ PaSMCs augmented the ability of BMP7 to induce Id1 or Smad6 gene expression, whereas silencing of 
A

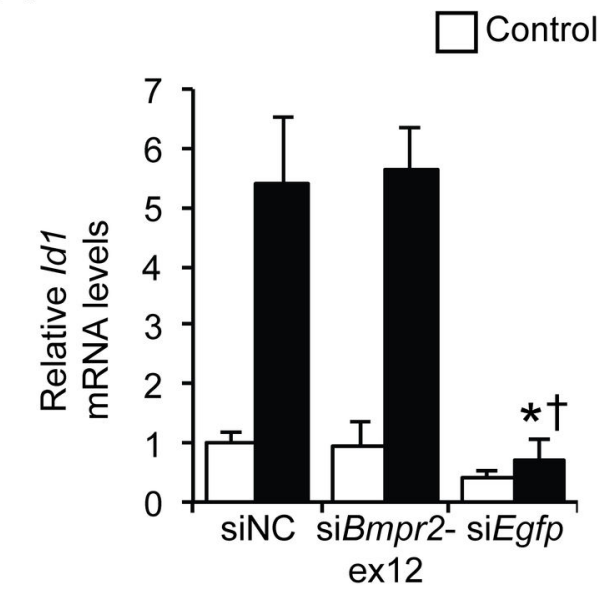

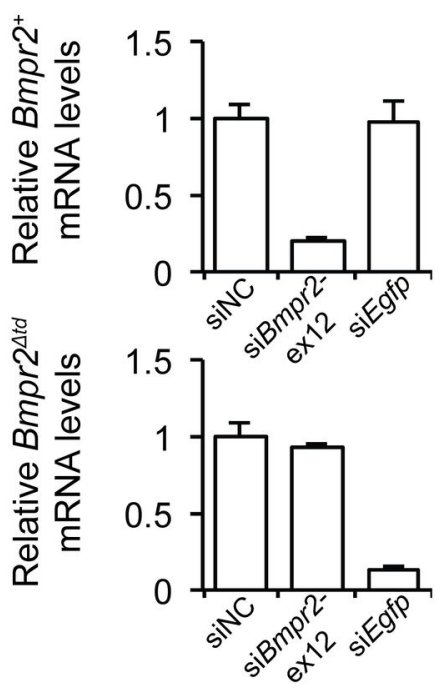

B
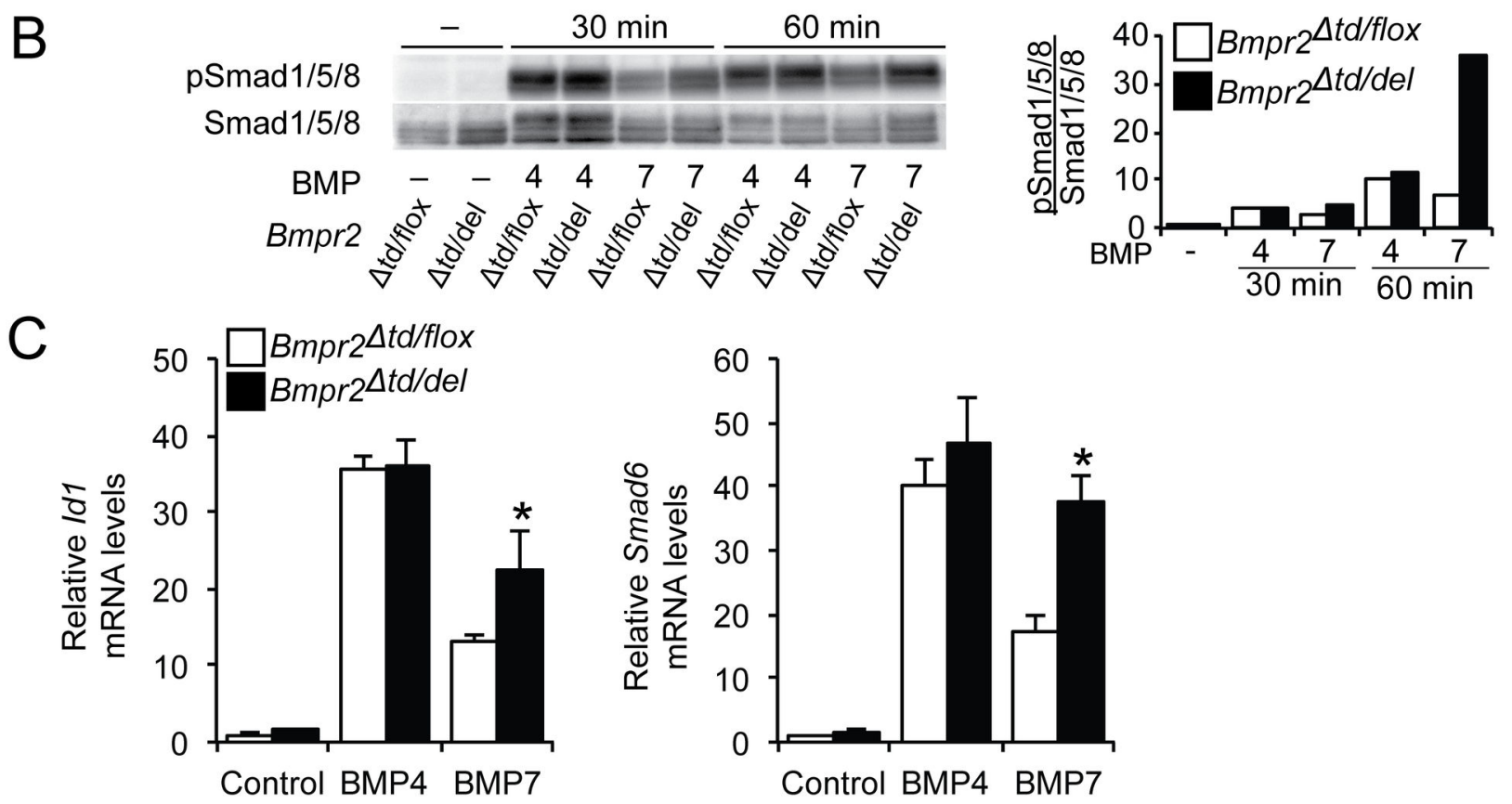

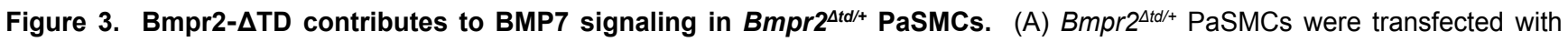
negative control siRNA (siNC), siBmpr2-ex12, or siEgfp (30 nM). After $48 \mathrm{~h}$, the ability of BMP7 (10 ng/ml for $1.5 \mathrm{~h})$ to induce ld1 and Smad6 mRNA expression was measured by qPCR, normalized to Gapdh and expressed as fold-change relative to Bmpr2 $2^{\Delta t d /+}$ PaSMCs transfected with siNC. ${ }^{*} \mathrm{P}<0.01$ compared to siNC group treated with BMP7, ${ }^{\dagger} \mathrm{P}<0.01$ compared to siBmpr2-ex12 group treated with BMP7. Efficiency of silencing Bmpr2+ (siBmpr2-ex12) and Bmpr2 ${ }^{\Delta t d}$ (siEgfp) transcripts was measured by qPCR. (B) $B m p r 2^{\Delta t d / f l o x}$ and Bmpr2 $2^{\Delta t d / d e l}$ PaSMCs were treated with BMP4 or BMP7 (10 ng/ml) for 30 and 60 minutes, upon which the activation of Smad1/5/8 was evaluated by immunoblotting. Quantification of the Smad1/5/8 activation is plotted as the ratio of $\mathrm{pSmad1/5/8}$ to total Smad1/5/8. (C) The ability of BMP4 or BMP7 to induce Id1 and Smad6 gene expression in Bmpr2 $2^{\Delta t d / f l o x}$ and Bmpr2 $2^{\Delta t d / d e l}$ PaSMCs was measured by qPCR, normalized to Gapdh and expressed as fold-change relative to untreated Bmpr2 ${ }^{\Delta t d / f l o x}$ PaSMCs. ${ }^{*} \mathrm{P}<0.01$ compared to Bmpr2 ${ }^{\Delta t d / f l o x} \mathrm{PaSMC}$ group treated with BMP7.

doi: 10.1371/journal.pone.0076947.g003

$B m p r 2^{\Delta t d}$ transcripts reduced the responsiveness of Bmpr2 $2^{\Delta t d /+}$; Alk3 ${ }^{\text {del/del }}$ PaSMCs to BMP7 (Figure 6). These results support the concept that BMP7 signaling is transduced by the mutant receptor Bmpr2- $\triangle T D$ and Alk2, and suggest that the tail domain of Bmpr2 may inhibit BMP7 signaling via Alk2. Deletion of both Alk2 and Alk3 abrogated BMP4 and BMP7 signaling in 


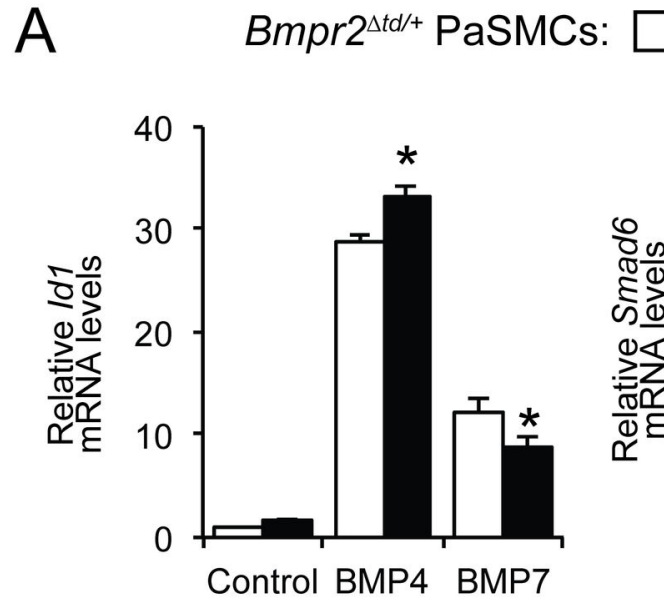
siNC $\square$ siAcvr2a

B

Bmpr2 ${ }^{\text {stddel }}$ PaSMCs: $\square$ siNC $\square$ siAcvr2a
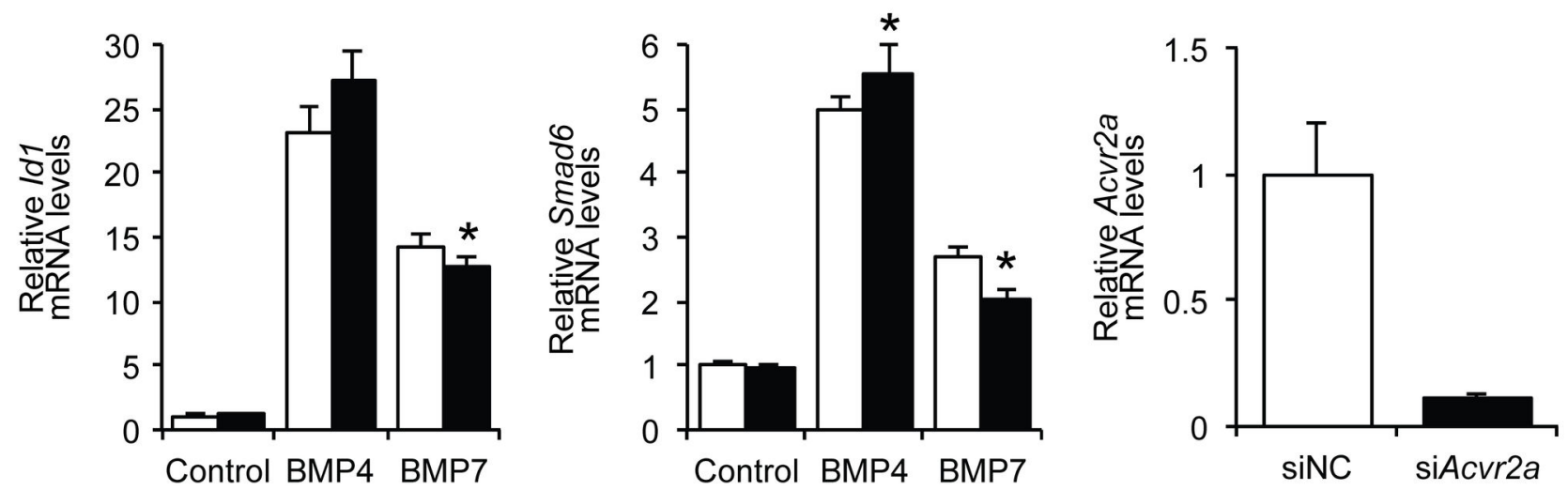

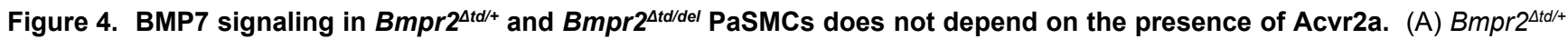
PaSMCs were treated with a siRNA specific for Acvr2a transcripts. The ability of BMP4 or BMP7 (10 ng/ml for $1.5 \mathrm{~h})$ to induce $/ d 1$ and Smad6 gene expression was measured by qPCR, normalized to Gapdh and expressed as fold-change relative to Bmpr2 ${ }^{\Delta t d /+}$ PaSMCs treated with siNC. ${ }^{*} P<0.01$ compared to siNC within BMP treatment. Silencing efficiency was quantified by measuring Acvr2a mRNA levels. (B) Bmpr2 ${ }^{\Delta t d / d e l}$ PaSMCs were treated with siAcvr2a. The ability of BMP4 or BMP7 (10 ng/ml for $\left.1.5 \mathrm{~h}\right)$ to induce $I d 1$ and Smad6 gene expression was measured by qPCR, normalized to Gapdh and expressed as fold-change relative to $B m p r 2^{\Delta t d / d e l}$ PaSMCs treated with siNC. ${ }^{*} \mathrm{P}<0.01$ compared to siNC within BMP treatment. Acvr2a silencing efficiency was measured by qPCR.

doi: 10.1371/journal.pone.0076947.g004

Bmpr2 ${ }^{\Delta t d /+}$ PaSMCs, as well as in Bmpr2 ${ }^{+/+}$PaSMCs (Figure S5). These findings suggested that the very low levels of Alk6 detected in PaSMCs are insufficient to transduce BMP signaling.

\section{Discussion}

In this study, we report the generation of a genetically modified mouse that carries a Bmpr2 allele with an NMDresistant mutation in the sequences encoding the Bmpr2-TD. We found that $B m p r 2^{\Delta t d / \Delta t d}$ mice die early in embryogenesis (E7.5-8.5) and that Bmpr2 ${ }^{\Delta t d /+}$ mice appear to grow normally. RVSP is similar in Bmpr $2^{\Delta t d /+}$ mice and their WT littermates at 6 to 8 months of age. We observed that the receptor encoded by the mutant allele, Bmpr2- $\Delta T D$, is expressed and traffics to the membrane of PaSMCs. In PaSMCs from Bmpr2 $2^{\Delta t d /+}$ mice, we found a BMP7-specific gain of signaling with preserved BMP4 signaling. Knockdown of $B m p r 2^{+}$transcripts in Bmpr2 $2^{\Delta t d /+}$ PaSMCs or deletion of the Bmpr2flox allele in conditional $B m p r 2^{\Delta t d f f l o x}$ PaSMCs showed that Bmpr2-WT is not required for these cells to transduce signaling in response to BMP7. However, knockdown of Bmpr2 $2^{\Delta t d}$ transcripts in Bmpr $2^{\Delta t d /+}$ PaSMCs inhibited BMP7 signaling. Finally, we determined that the increased responsiveness of Bmpr2 ${ }^{\Delta t d /+}$ PaSMCs to BMP7 relies on the presence of Alk2, thus revealing that the tail domain of Bmpr2 inhibits Alk2-mediated signaling. 
A
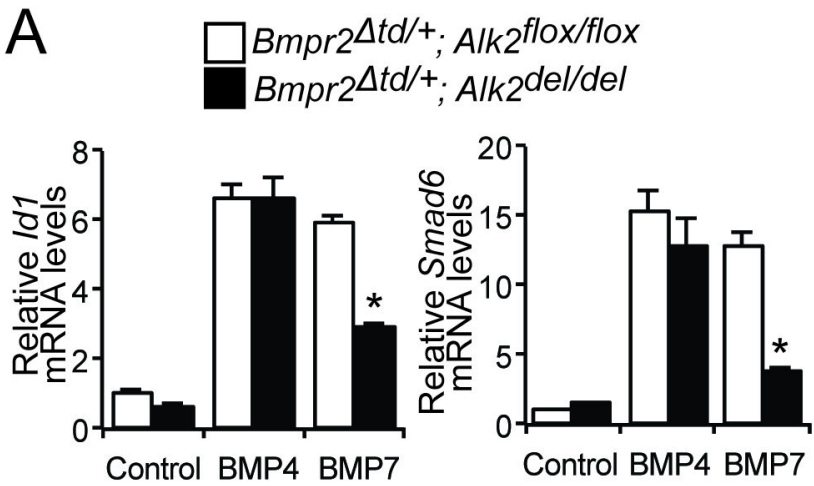

B $\begin{aligned} & \square m p r 2^{\Delta t d /+} ; A l k 3^{\text {flox/flox }} \\ & B m p r 2^{\Delta t d /+} ; A l k 3^{d e l / d e l}\end{aligned}$

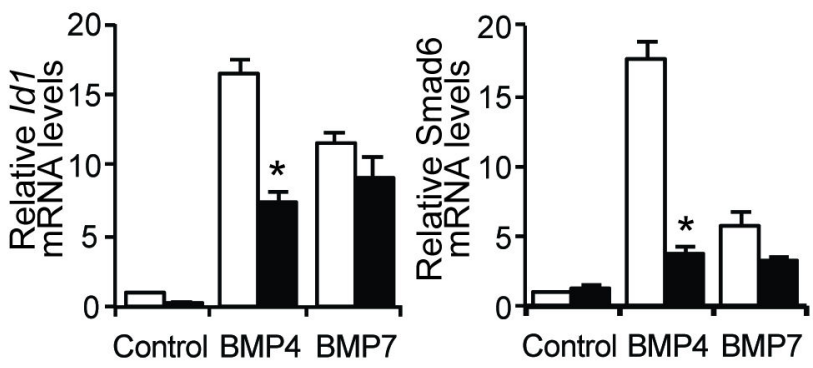

Figure 5. BMP7 preferentially utilizes Alk2 in Bmpr2 $2^{\Delta t d /+}$ PaSMCs. (A) The ability of BMP4 or BMP7 (10 ng/ml for $1.5 \mathrm{~h})$ to induce $I d 1$ and Smad6 gene expression, in Bmpr2 $2^{\Delta t d /+}$ PaSMCs deficient in Alk2 or expressing Alk2 was examined by qPCR. Id1 and Smad6 gene expression was normalized to Gapdh and expressed as fold-change relative to $B m p r 2^{\Delta t d /+}$; Alk2 flox/flox PaSMCs. *P $<0.01$ compared to Bmpr2 ${ }^{\Delta t d /+}$; Alk2 floxflox PaSMCs treated with BMP7. (B) The ability of BMP4 or BMP7 $(10 \mathrm{ng} / \mathrm{ml}$ for $1.5 \mathrm{~h}$ ) to induce Id1 and Smad6 gene expression, in Bmpr2 ${ }^{\Delta t d /+}$ PaSMCs deficient in Alk3 or expressing Alk3 was measured by qPCR. Id 1 and Smad6 gene expression was normalized to Gapdh and expressed as fold-change relative to Bmpr2 ${ }^{\Delta t d /+} ;$ Alk3 floxflox PaSMCs. ${ }^{*} \mathrm{P}<0.01$ compared to Bmpr2 $2^{\Delta t d /+} ; A l k 3^{\text {floxfllox }}$ PaSMC treated with BMP4.

doi: 10.1371/journal.pone.0076947.g005

In the process of posttranscriptional regulation, the mRNA surveillance mechanism of NMD plays a critical role degrading aberrant transcripts prior to translation $[16,17]$. It was conceivable that transcripts generated by the Bmpr2 ${ }^{\Delta t d}$ allele would undergo NMD. We observed, however, that Bmpr2 ${ }^{\Delta t d}$ mRNA represented half of the Bmpr2 transcripts expressed in $B m p r 2^{\Delta t d /+}$ PaSMCs. Likewise, Bmpr2- $\Delta$ TD protein expression was readily detected in lysates from PaSMCs expressing the $B m p r 2^{\Delta t d}$ allele. These data show that transcripts from the $B m p r 2^{\Delta t d}$ allele were resistant to NMD. Our mouse model differs from other genetically modified mice carrying mutations in the Bmpr2-TD. Mutant transcripts from heterozygous mice carrying a BMPR2 R899X knockin allele were found to be subject to NMD [21], rendering these knockin mice similar to
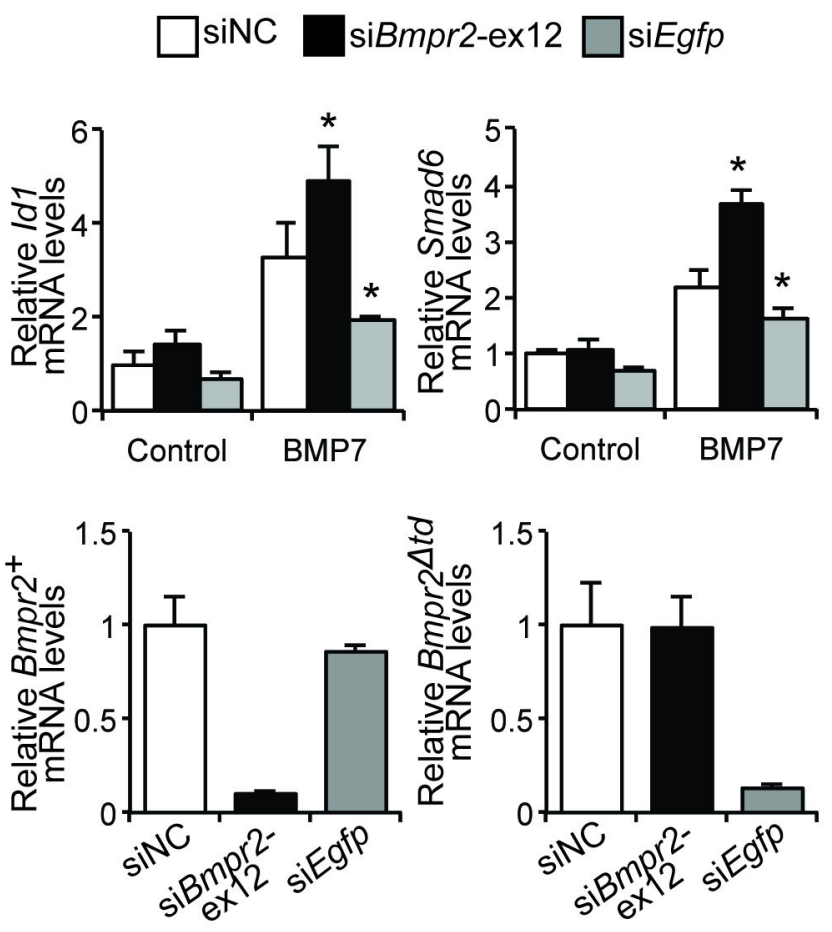

Figure 6. Bmpr2-TD attenuates Alk2-mediated BMP7 signaling in PaSMCs. Alk3-deficient $B m p r 2^{\Delta t d /+} \mathrm{PaSMCs}$ were transfected with specific siRNA to silence $B m p r 2^{+}$ (siBmpr2-ex12) or Bmpr2 ${ }^{\Delta t d}$ (siEgfp) transcripts. After $48 \mathrm{~h}$, the ability of BMP7 to induce Id 1 and Smad6 gene expression was measured by qPCR, normalized to Gapdh and expressed as fold-change relative to $B m p r 2^{\Delta t d /+} ; A l k 3^{\text {del/del }}$ PaSMCs treated with siNC. ${ }^{*} \mathrm{P}<0.01$ compared to control cells (siNC) treated with BMP7. Silencing efficiency was quantified by qPCR.

doi: 10.1371/journal.pone.0076947.g006

haploinsufficient $\mathrm{Bmpr}^{+/}$mice. In contrast, BMPR2 R899X protein was detected in the pulmonary vasculature of mice in which a transgene specifying the mutant protein was inducibly overexpressed in smooth muscle cells [22].

Mice with Bmpr2 mutations have been used to study how human BMPR2 mutations might predispose carriers to $\mathrm{PAH}$. $\mathrm{Bmpr}^{+/-}$mice express about $50 \%$ of $\mathrm{Bmpr}^{+}$mRNA levels and manifest little [18] or no [23,24] pulmonary hypertension at baseline; however, pulmonary hypertension induced by an inflammatory stress [24] or an infusion of serotonin [23] is more marked in $\mathrm{Bmpr}^{+/-}$than in WT mice. Mice carrying one copy of a mutant Bmpr2 allele lacking exon 2 (Bmpr2 $\left.2^{\triangle E 2}\right)$ do not manifest pulmonary hypertension at baseline but develop more marked pulmonary hypertension after prolonged exposure to hypoxia [25]. Although the main objective of our work was to study the role of the tail domain of Bmpr2 using cells from $B m p r 2^{\Delta t d /+}$ mice, we did examine whether $B m p r 2^{\Delta t d /+}$ mice spontaneously develop pulmonary hypertension. At baseline, RVSP does not differ in 6- to 8-month-old Bmpr2 $2^{\Delta t d /+}$ and WT mice. The absence of pulmonary hypertension at baseline in mice carrying heterozygous Bmpr2 mutations (with mutant Bmpr2 alleles expressed at levels similar to those of the WT 
allele) is consistent with the observation that $\mathrm{PAH}$ occurs in only one-fifth of the individuals harboring BMPR2 mutations, suggesting that additional genetic or environmental factors (second hit) are involved in the clinical manifestation of the disease [14].

BMPs are involved in numerous processes during early embryonic development including organogenesis and morphogenesis [1]. We previously demonstrated that Bmpr2-embryos are arrested during gastrulation [26]. In contrast, mice homozygous for a hypomorphic Bmpr2 (Bmpr2 $\left.{ }^{\triangle E 2 / \triangle E 2}\right)$, which appears to retain some BMP signaling capabilities, are able to complete gastrulation, but die during midgestation due to defects in the organogenesis of the cardiovascular and skeletal systems [27]. In the present study, we observed that homozygous Bmpr2 $2^{\Delta t d / \Delta t d}$ mice die in gastrulation even though the Bmpr2- $\triangle$ TD mutant retains the ability to activate Smads in response to BMP ligands. These observations show that embryogenesis not only requires Bmpr2 kinase activity, but also the presence of the tail domain of Bmpr2.

To begin to understand how BMP signaling is modulated by the absence of the tail domain of $\mathrm{Bmpr} 2$, we tested the responsiveness of Bmpr2 $2^{\Delta t d /+}$ PaSMCs to BMP4 and BMP7 and found an unexpected BMP7-specific gain of function. We considered several possible mechanisms by which this gain of function might occur. First, we considered the possibility that the absence of the Bmpr2-TD would alter the ability of the receptor to traffic and localize to the cell membrane. In Xenopus embryos, the neuroectodermal protein Jiraiya interacts with a motif in the Bmpr2-TD to inhibit bmpr2 trafficking to the cell membrane [28], suggesting that loss of the tail domain may facilitate the trafficking of the receptor to the cellular membrane. Moreover, it has been reported that BMPR2 proteins with mutations in the tail domain can traffic to the cellular membrane and can transduce BMP signaling $[29,30]$. Similarly, we observed that Bmpr2- $\Delta$ TD localized to the cell membrane of PaSMCs. Taken together, these findings demonstrate that the Bmpr2-TD is not required for trafficking of the receptor to the cell surface.

Previous reports have identified several proteins that can interact with the tail domain of BMPR2 and regulate BMP signaling. Tribbles homolog 3 (Trib3) interacts with the BMPR2TD and dissociates from the receptor upon BMP4 binding and activation of the receptor complex [8]. Once unbound, Trib3 promotes the ubiquitination of SMURF1 (SMAD-specific E3 ubiquitin-protein ligase 1), thereby enhancing BMP signaling by reducing the degradation of activated SMADs. Another protein interacting with the BMPR2-TD, cGMP-dependent protein kinase type I (PKG), phosphorylates the receptor leading to enhanced BMP signaling [9]. Following BMP2 binding to the receptor complex, PKG dissociates from the BMPR2-TD and binds to activated SMADs and enhances their transcriptional activity. However, loss of Trib3 or PKG binding to the tail domain of BMPR2 is unlikely to explain the BMP7-specific increased responsiveness of cells expressing Bmpr2- $\triangle T D$.

We previously reported that Acvr2a transduced BMP4 signaling and was required for the enhanced BMP7 signaling found in PaSMCs lacking Bmpr2 (Bmpr2 $\left.{ }^{\text {del/del }}\right)$ [5]. We considered the possibility that the BMP7-specific gain of function seen in PaSMCs carrying the Bmpr2 $2^{\Delta t d}$ allele was exclusively transduced by Acvr2a. We observed, however, that silencing of the Bmpr $2^{\Delta t d}$ allele in Bmpr2 $2^{\Delta t d /+}$ PaSMCs markedly reduced BMP7 signaling. Moreover, silencing Acvr2a transcripts only modestly affected the ability of $B m p r 2^{\Delta t d /+}$ or $B m p r 2^{\Delta t d / d e l}$ PaSMCs to transduce BMP7 signaling. These results demonstrate that the enhanced BMP7 signaling seen in PaSMCs carrying the Bmpr2 $2^{\Delta t d}$ allele is predominantly mediated by Bmpr2- $\Delta$ TD rather than by Acvr2a. We previously reported that knockdown of Acvr2a expression reduced BMP

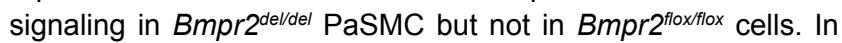
our current studies, we observed that BMP7 signaling was greater in Bmpr2 ${ }^{\Delta t d / d d l}$ PaSMCs than in Bmpr2 $2^{\Delta t d / f l o x}$ PaSMCs. Taken together, these observations suggest that the tail domain of Bmpr2 can suppress BMP7 signaling transduced by either Acvr2a or Bmpr2- $\triangle$ TD.

Different BMPs have distinct affinities for each of the BMP receptors. For example, BMP7 has a higher affinity for Alk2 than for other BMP type 1 receptors $[19,20]$. We therefore tested the hypothesis that the enhanced BMP7 signaling seen in cells expressing Bmpr2- $\triangle T D$ is mediated by Alk2. In $B m p r 2^{\Delta t d /+}$ PaSMCs, deletion of Alk3 markedly reduced BMP4 signaling but not BMP7 signaling. In contrast, we observed that deletion of Alk2 markedly impaired the ability of Bmpr2- $\Delta$ TD to transduce BMP7 signals. These results demonstrate that Bmpr2- $\triangle T$ TD and Alk2 mediate BMP7 signaling in cells harboring the Bmpr2 $2^{\Delta t d}$ allele. Taken together with our observations in Bmpr2 ${ }^{\text {del/del }}$ PaSMC, these findings suggest that the tail domain of Bmpr2 suppresses Alk2-dependent BMP7 signaling by either Bmpr2- $\triangle T D$ or Acvr2a and raise the possibility that the the tail domain of Bmpr2 directly inhibits Alk2 function. Unfortunately, currently available commercial antibodies detect BMP type I receptors only when they are overexpressed, hampering the detection of interactions of endogenously expressed BMP receptors.

In conclusion, we report the generation of a mouse harboring an NMD-resistant mutation in the sequences encoding for the Bmpr2-TD. Mice homozygous for the mutant allele died early in embryogenesis, possibly because of a critical role for Bmpr2-TD in gastrulation. Heterozygous mice grow normally and, as observed in genetically modified mice carrying other mutant Bmpr2 alleles, they did not spontaneously develop $\mathrm{PAH}$. The BMP7-specific gain of function observed in PaSMCs from heterozygous Bmpr2 ${ }^{\Delta t d /+}$ mice was mediated by the mutant receptor and the BMP type 1 receptor, Alk2. Our data suggest that BMP7 signaling is inhibited in WT PaSMCs by a restriction exerted by the Bmpr2-TD over Alk2. These data also raise the possibility that some disease-causing BMPR2 mutations may alter BMP signaling in a BMP ligand-specific manner.

\section{Material and Methods}

\section{Generation of mice carrying mutant BMP receptors}

The strategy to create the Bmpr2 $2^{\Delta t d}$ allele is shown in Figure $\mathrm{S} 1 \mathrm{~A}$. The Bmpr2 ${ }^{\Delta t d}$-targeting vector carries sequences for Egfp (in frame after exon 11), the SV40 polyadenylation signal (SV40pA), and a phosphoglycerol kinase promoter-controlled neomycin-resistance gene (PGK-neo) cassette after exon 11. 
Mouse embryonic stem (ES) cells were transfected with the targeting vector, and Southern blot analysis identified an ES cell clone with homologous recombination (Figure S1B). The recombinant ES cells were injected into blastocysts and germline transmission was achieved. Removal of the PGK-neo cassette, flanked by loxP sequences, was achieved by mating the heterozygous $B m p r 2^{\Delta t d /+}$ mice with Ella-Cre transgenic mice. Mice heterozygous for the $B m p r 2^{\Delta t d}$ allele were derived from crossing chimeric mice with C57BL/6 female mice. PCR analysis for genotyping purposes using DNA isolated from E7.5 embryos is shown in Figure S1C. Genotyping primers for the mutant Bmpr2 $2^{\Delta t d}$ allele are 5'GTGCTACAGGCAGTGAGGTCACTC-3' and 5'TAGGTCAGGGTGGTCACGAGGGTG-3' (400-bp product). Genotyping primers for $\mathrm{Bmpr}^{+}$allele are 5'GACTTCACACAGGCTGCAAATGGG-3' and 5'CATACTGGGTTGTGGCAGCATGGG-3' (300-bp product).

$B m p r 2^{\Delta t d /+}$ mice were backcrossed more than 9 times onto a C57BL/6 background. Bmpr2flox/flox mice [31] bred onto C57BL/6 background were bred to $B m p r 2^{\Delta t d /+}$ mice to generate $B m p r 2^{\Delta t d /}$ flox mice. Alk2 floxfllox mice on a mixed C57BL/6; SV129 background [32] or $A l k 3^{\text {floxflox }}$ mice on a C57BL/6 background [33] were bred to $B m p r 2^{\Delta t d /+}$ mice to generate $B m p r 2^{\Delta t d /+}$; $A l k 2^{\text {floxfllox }}$, or Bmpr $2^{\Delta t d /+} ; A l k 3^{\text {flox/flox }}$ mice, respectively.

All animal experiments were conducted under protocols reviewed and approved by the Subcommittee on Research and Animal Care of the Massachusetts General Hospital.

\section{Hemodynamic measurements in Bmpr2 ${ }^{\Delta t d /+}$ and WT mice}

Mice were anesthetized with ketamine $(100 \mathrm{mg} / \mathrm{kg})$ and fentanyl $(250 \mu \mathrm{g} / \mathrm{kg})$ intraperitoneally, intubated, and mechanically ventilated $\left(10 \mu \mathrm{l} / \mathrm{g}, 100\right.$ breaths per minute; $\mathrm{FiO}_{2}$ $=$ 1). Pancuronium $(2 \mathrm{mg} / \mathrm{kg})$ was administered intraperitoneally, and a PE-10 polyethylene catheter was placed in the left carotid artery for continuous measurement of heart rate and systemic arterial pressure. A 1.2F high-fidelity pressure catheter (FTS-1211B-0018; Scisense, London, ON, Canada) was advanced into the right ventricle via the jugular vein to measure right ventricular systolic pressure (RVSP), as an estimate of pulmonary arterial systolic pressure. All signals were recorded and analyzed using a data acquisition system ( $A$ D Instruments, Colorado Springs, CO). At the end of the study mice were euthanized with an intraperitoneal injection of pentobarbital $(200 \mathrm{mg} / \mathrm{kg})$.

\section{PaSMC isolation and culture}

Mice were euthanized with an intraperitoneal injection of pentobarbital $(200 \mathrm{mg} / \mathrm{kg}$ ). Pulmonary arteries (PA) were isolated and incubated individually in trypsin-EDTA for $10 \mathrm{~min}$ at $37^{\circ} \mathrm{C}$. PAs were cut into $\sim \mathrm{mm}^{3}$ pieces and enzymatically digested using a solution of collagenase, papain, elastase, and soybean trypsin inhibitor for $30 \mathrm{~min}$ at $37^{\circ} \mathrm{C}$. After dissociation, cells were washed twice in DMEM containing $20 \%$ fetal bovine serum. After the final wash, cells were resuspended in DMEM with $20 \%$ FBS and antibiotics (penicillin - streptomycin) and were cultured at $37^{\circ} \mathrm{C}$ in $10 \% \mathrm{CO}_{2}$. After the first passage, cells were grown in DMEM containing 10\% FBS. Cells were used for experiments between passages 3 and 10 .

\section{Adenovirus infection}

To disrupt Bmpr2, Alk2, or Alk3 genes in PaSMCs isolated from mice harboring alleles carrying loxP sequences, cells were infected with Ad-Cre or Ad-RFP, as a control, at a multiplicity of infection of 150. After cells recovered from infection, efficiency of recombination of the Bmpr2 allele flanked by loxP sequences was determined by PCR and immunoblot techniques, as reported previously [31]. Efficiency of recombination of Alk2 or Alk3 alleles flanked by loxP sequences was determined by qPCR using hydrolysis probes.

\section{Small interfering RNA inhibition of BMP receptors}

Silencer® Select siRNA (Applied Biosystems, Life Technologies) specific for Bmpr2, Egfp, and Acvr2a or negative control siRNA (30-50 nM) were transfected into PaSMCs using Pepmute siRNA transfection reagent (SignaGen Laboratories), as described by the manufacturer. After 48 hours, transfected cells were starved in DMEM with $0.1 \%$ FBS for 12 to 16 hours and then treated with BMP4 or BMP7.

\section{Gene expression}

Total RNA was extracted by guanidine isothiocyanate/phenol method. cDNA was synthesized using M-MLV reverse transcriptase and random primers (Promega). Id1, Smad6, Bmpr2, Egfp, Acvr2a, Alk2, Alk3 and Gapdh transcript levels were measured by qPCR in a Mastercycler ep realplex 2 (Eppendorf) using hydrolysis probes (TaqMan ${ }^{\circledR}$ Gene Expression Assays, Applied Biosystems, Life Technologies) and Probe Fast Master Mix (Kapa Biosystems). qPCR reactions were prepared using the specific FAM-labeled hydrolysis probes and the Gapdh VIC-labeled primer-limited hydrolysis probe, as internal reference gene. Changes in relative gene expression normalized to Gapdh mRNA levels were determined using the relative $\mathrm{C}_{\mathrm{T}}$ method.

\section{Immunoblot techniques}

Confluent PaSMCs were incubated with DMEM with $0.1 \%$ FBS for 12 to 16 hours and then treated for various times with BMP4 or BMP7. Cells were lysed with RIPA buffer containing proteinase and phosphatase inhibitor cocktails (Sigma). Lysates were mixed with NuPAGE ${ }^{\circledR}$ LDS sample buffer (Invitrogen, Life Technologies) containing $1 \mathrm{mM}$ DTT. Proteins were separated by NuPAGE $®$ Bis-Tris gels (Invitrogen, Life Technologies), transferred to polyvinylidene difluoride membranes (Immobilon-FL, Millipore), and blocked in TBS containing $5 \%$ skim milk and $0.1 \%$ Tween 20 . Membranes were reacted with antibodies directed against phosphorylated Smad1/5/8, Gapdh (Cell Signaling); as well as total Smad1/5/8 (Santa Cruz Biotechnology), the tail domain of Bmpr2 (BD Transduction Laboratories), or GFP (Roche). After incubation with HRP-conjugated IgG secondary antibodies (Epitomics and Cell Signaling) and ECL Plus reagent (GE Healthcare Life Sciences), chemifluorescence signals were detected with a 
Versadoc® Imaging Systems. Captured images were analyzed with ImageJ software (NIH).

\section{Immunofluorescence labeling}

PaSMCs were transiently transfected with a plasmid carrying the sequences of Bmpr2- $\Delta$ TD. After 16 hours, cells were fixed with $4 \%$ paraformaldehyde in PBS and permeabilized with $0.1 \%$ Triton $\mathrm{X}-100$ in PBS. Immunohistochemical staining was performed with a mouse anti-GFP antibody (Invitrogen, Life Technologies), followed by incubation with fluorescein isothiocyanate-labeled goat anti-mouse lgG. Subcellular localization of Bmpr2- $\Delta T D$ was determined by confocal laser scanning microscopy.

\section{Statistics}

Differences between groups were determined using two-way ANOVA for experiments using cultured PaSMCs. Figures show results representative of three or more PaSMC isolates for each genotype. For qPCR experiments, each experimental condition was performed in quadruplicate. All data are expressed as means \pm standard deviation. The Student t-test was used to analyze mouse hemodynamic measurements (HR, MAP, RVSP). A value of $p<0.05$ indicated a significant difference.

\section{Supporting Information}

Figure S1. Bmpr2 ${ }^{\Delta t d}$ gene-targeting strategy. (A) Schematic diagrams (from top to bottom) of the wild-type Bmpr2 gene, the targeting vector, and the mutant $B m p r 2^{\Delta t d}$ allele after homologous recombination. The entire tail domain of Bmpr2 is encoded by exon 12 and 13. A genomic fragment containing intron 11 and exon 12 was replaced by the sequence of Egfp (in frame after exon 11) followed by SV40 polyA signal and a PGK-neo cassette. (B) Southern blot analysis of DNA isolated from ES clones. (C) PCR genotyping analysis of E7.5 embryos generated by intercrosses of $F 1$ heterozygotes. (TIF)

Figure S2. Hemodynamic measurements in $\mathrm{Bmpr2}^{+/+}$and Bmpr2 $^{\Delta t d /+}$ mice. Heart rate (HR), mean systemic arterial pressure (MAP), and right ventricular systolic pressure (RVSP) were measured in 6- to 8-month-old mice (littermates).

(TIF)

Figure S3. Id1 gene expression in Bmpr2 $2^{+/+}$and $B m p r 2^{\Delta t d /+}$ PaSMCs after 24 hours treatment with BMP4 or BMP7 (10 $\mathrm{ng} / \mathrm{ml}$; ${ }^{*} \mathrm{p}<0.01$ versus without BMP ligand).

\section{References}

1. Kishigami S, Mishina $Y$ (2005) BMP signaling and early embryonic patterning. Cytokine Growth Factor Rev 16: 265-278. doi:10.1016/ j.cytogfr.2005.04.002. PubMed: 15871922.

2. Miyazono K, Kamiya Y, Morikawa M (2010) Bone morphogenetic protein receptors and signal transduction. J Biochem 147: 35-51. doi: 10.1093/jb/mvp148. PubMed: 19762341.
(TIF)

Figure S4. Immunoblotting of Bmpr2 $2^{\Delta t d / f l o x}$ and Bmpr2 $2^{\Delta t d / d e l}$ PaSMCs with anti-Bmpr2-TD to detect Bmpr2-WT or antiGFP to detect Bmpr2-ATD. Gapdh was used as loading control.

(TIF)

Figure S5. Concomitant loss of Alk2 and Alk3 prevents

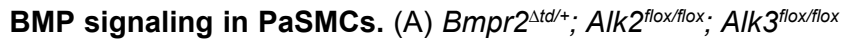

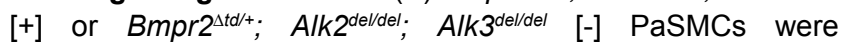
stimulated with BMP4 or BMP7 $(10 \mathrm{ng} / \mathrm{ml})$ for $30 \mathrm{~min}$ or $1 \mathrm{~h}$. Immunoblotting for pSmad1/5/8 and Smad1/5/8 show that $B m p r 2^{\Delta t d /+}$ PaSMCs lacking the expression of Alk2 and Alk3 have lost the ability to phosphorylate BMP-responsive Smad1/5/8. (B) $B m p r 2^{+/+} ; A l k 2^{\text {floxflox; }} A l k 3^{\text {floxflox }}$ or $B m p r 2^{+/+}$; Alk2 ${ }^{\text {del/del; }}$ Alk3 $3^{\text {del/del }}$ PaSMCs were stimulated with BMP4 or BMP7 $(10 \mathrm{ng} / \mathrm{ml})$ for $2 \mathrm{~h}$, and the ability to induce $/ d 1$ and Smad6 gene expression was measured by qPCR. Bmpr2 ${ }^{+/+}$ PaSMCs lacking expression of Alk2 and Alk3 have lost the ability to induce $I d 1$ and Smad6 gene expression in response to BMP ligands. (C) Bmpr2 $2^{\Delta t d /+} ; A l k 2^{\text {floxfllox; }} A / k 3^{\text {floxflox }}$ or $B m p r 2^{\Delta t d /+} ; A l k 2^{\text {del/del }} ; A l k 3^{\text {del/del }}$ PaSMCs were stimulated with BMP4 or BMP7 $(10 \mathrm{ng} / \mathrm{ml})$ for $2 \mathrm{~h}$, and the ability to induce $/ d 1$ and Smad6 gene expression was measured by qPCR. Bmpr2 ${ }^{\Delta t d /+}$ PaSMCs lacking expression of Alk2 and Alk3 have lost the ability to induce $I d 1$ and Smad6 gene expression in response to BMP ligands.

(TIF)

\section{Acknowledgements}

The authors thank Yushi Mishina and Vesa Kaartinen for providing $\mathrm{Alk}^{+/ f l l o x}$ and $\mathrm{Alk}^{+/ f l o x}$ mice, respectively; Noriko Kawai, Sharon M. Cawley and Andrea U. Steinbicker for valuable technical advice; and Francesco Nordio and Andrea Bellavia for statistical analyses.

\section{Author Contributions}

Conceived and designed the experiments: PAL HB KDB. Performed the experiments: PAL HB AP TMM MD DMB RG DBB. Analyzed the data: PAL HB AP TMM DMB DBB KDB. Wrote the manuscript: PAL HB KDB.

3. Schmierer B, Hill CS (2007) TGFbeta-SMAD signal transduction: molecular specificity and functional flexibility. Nat Rev Mol Cell Biol 8: 970-982. doi:10.1038/nrm2297. PubMed: 18000526.

4. Sieber C, Kopf J, Hiepen C, Knaus P (2009) Recent advances in BMP receptor signaling. Cytokine Growth Factor Rev 20: 343-355. doi: 10.1016/j.cytogfr.2009.10.007. PubMed: 19897402.

5. Yu PB, Beppu H, Kawai N, Li E, Bloch KD (2005) Bone morphogenetic protein (BMP) type II receptor deletion reveals BMP ligand-specific gain 
of signaling in pulmonary artery smooth muscle cells. J Biol Chem 280: 24443-24450. doi:10.1074/jbc.M502825200. PubMed: 15883158.

6. Kawabata M, Chytil A, Moses HL (1995) Cloning of a novel type II serine/threonine kinase receptor through interaction with the type I transforming growth factor-beta receptor. J Biol Chem 270: 5625-5630. doi:10.1074/jbc.270.10.5625. PubMed: 7890683.

7. Beppu H, Minowa O, Miyazono K, Kawabata M (1997) cDNA cloning and genomic organization of the mouse BMP type II receptor. Biochem Biophys Res Commun 235: 499-504. doi:10.1006/bbrc.1997.6816. PubMed: 9207184

8. Chan MC, Nguyen PH, Davis BN, Ohoka N, Hayashi H et al. (2007) A novel regulatory mechanism of the bone morphogenetic protein (BMP) signaling pathway involving the carboxyl-terminal tail domain of BMP type II receptor. Mol Cell Biol 27: 5776-5789. doi:10.1128/MCB. 00218-07. PubMed: 17576816.

9. Schwappacher R, Weiske J, Heining E, Ezerski V, Marom B et al. (2009) Novel crosstalk to BMP signalling: cGMP-dependent kinase I modulates BMP receptor and Smad activity. EMBO J 28: 1537-1550. doi:10.1038/emboj.2009.103. PubMed: 19424179.

10. Morse JH, Jones AC, Barst RJ, Hodge SE, Wilhelmsen KC et al. (1997) Mapping of familial primary pulmonary hypertension locus (PPH1) to chromosome 2q31-q32. Circulation 95: 2603-2606. doi: 10.1161/01.CIR.95.12.2603. PubMed: 9193425.

11. Nichols WC, Koller DL, Slovis B, Foroud T, Terry VH et al. (1997) Localization of the gene for familial primary pulmonary hypertension to chromosome 2q31-32. Nat Genet 15: 277-280. doi:10.1038/ ng0397-277. PubMed: 9054941.

12. McLaughlin VV, Archer SL, Badesch DB, Barst RJ, Farber HW et al. (2009) ACCF/AHA 2009 expert consensus document on pulmonary hypertension a report of the American College of Cardiology Foundation Task Force on Expert Consensus Documents and the American Heart Association developed in collaboration with the American College of Chest Physicians; American Thoracic Society, Inc.; and the Pulmonary Hypertension Association. J Am Coll Cardiol 53: 1573-1619. doi:10.1016/j.jacc.2009.01.004. PubMed: 19389575.

13. Fessel JP, Loyd JE, Austin ED (2011) The genetics of pulmonary arterial hypertension in the post-BMPR2 era. Pulm Circ 1: 305-319. doi: 10.4103/2045-8932.87293. PubMed: 22140620.

14. Machado RD, Aldred MA, James V, Harrison RE, Patel B et al. (2006) Mutations of the TGF-beta type II receptor BMPR2 in pulmonary arterial hypertension. Hum Mutat 27: 121-132. doi:10.1002/humu.20285. PubMed: 16429395.

15. Cogan JD, Pauciulo MW, Batchman AP, Prince MA, Robbins IM et al. (2006) High frequency of BMPR2 exonic deletions/duplications in familial pulmonary arterial hypertension. Am J Respir Crit Care Med 174: 590-598. doi:10.1164/rccm.200602-1650C. PubMed: 16728714

16. Hamid R, Hedges LK, Austin E, Phillips JA 3rd, Loyd JE et al. (2010) Transcripts from a novel BMPR2 termination mutation escape nonsense mediated decay by downstream translation re-initiation: implications for treating pulmonary hypertension. Clin Genet 77: 280-286. doi:10.1111/j.1399-0004.2009.01311.x. PubMed: 20095988.

17. Austin ED, Phillips JA, Cogan JD, Hamid R, Yu C et al. (2009) Truncating and missense BMPR2 mutations differentially affect the severity of heritable pulmonary arterial hypertension. Respir Res 10: 87. doi:10.1186/1465-9921-10-87. PubMed: 19785764.

18. Beppu H, Ichinose F, Kawai N, Jones RC, Yu PB et al. (2004) BMPR-II heterozygous mice have mild pulmonary hypertension and an impaired pulmonary vascular remodeling response to prolonged hypoxia. Am J Physiol Lung Cell Mol Physiol 287: L1241-L1247. doi:10.1152/ajplung. 00239.2004. PubMed: 15286002.

19. Aoki H, Fujii M, Imamura T, Yagi K, Takehara K et al. (2001) Synergistic effects of different bone morphogenetic protein type I receptors on alkaline phosphatase induction. J Cell Sci 114: 1483-1489. PubMed: 11282024

20. ten Dijke P, Yamashita H, Sampath TK, Reddi AH, Estevez M et al. (1994) Identification of type I receptors for osteogenic protein-1 and bone morphogenetic protein-4. J Biol Chem 269: 16985-16988. PubMed: 8006002

21. Nasim MT, Ogo T, Chowdhury HM, Zhao L, Chen CN et al. (2012) BMPR-II deficiency elicits pro-proliferative and anti-apoptotic responses through the activation of TGFbeta-TAK1-MAPK pathways in $\mathrm{PAH}$. Hum Mol Genet 21: 2548-2558. doi:10.1093/hmg/dds073. PubMed: 22388934.

22. West J, Harral J, Lane K, Deng Y, Ickes B et al. (2008) Mice expressing BMPR2R899X transgene in smooth muscle develop pulmonary vascular lesions. Am J Physiol Lung Cell Mol Physiol 295: L744-L755. doi:10.1152/ajplung.90255.2008. PubMed: 18723761

23. Long L, MacLean MR, Jeffery TK, Morecroft I, Yang X et al. (2006) Serotonin increases susceptibility to pulmonary hypertension in BMPR2-deficient mice. Circ Res 98: 818-827. doi:10.1161/01.RES. 0000215809.47923.fd. PubMed: 16497988.

24. Song Y, Jones JE, Beppu H, Keaney JF Jr., Loscalzo J et al. (2005) Increased susceptibility to pulmonary hypertension in heterozygous BMPR2-mutant mice. Circulation 112: 553-562. doi:10.1161/ CIRCULATIONAHA.104.492488. PubMed: 16027259.

25. Frank DB, Lowery J, Anderson L, Brink M, Reese J et al. (2008) Increased susceptibility to hypoxic pulmonary hypertension in Bmpr2 mutant mice is associated with endothelial dysfunction in the pulmonary vasculature. Am J Physiol Lung Cell Mol Physiol 294: L98-109. PubMed: 18024717

26. Beppu H, Kawabata M, Hamamoto T, Chytil A, Minowa O et al. (2000) BMP type II receptor is required for gastrulation and early development of mouse embryos. Dev Biol 221: 249-258. doi:10.1006/dbio. 2000.9670. PubMed: 10772805.

27. Délot EC, Bahamonde ME, Zhao M, Lyons KM (2003) BMP signaling is required for septation of the outflow tract of the mammalian heart. Development 130: 209-220. doi:10.1242/dev.00181. PubMed: 12441304.

28. Aramaki T, Sasai N, Yakura R, Sasai Y (2010) Jiraiya attenuates BMP signaling by interfering with type II BMP receptors in neuroectodermal patterning. Dev Cell 19: 547-561. doi:10.1016/j.devcel.2010.09.001. PubMed: 20951346

29. Nishihara A, Watabe T, Imamura T, Miyazono K (2002) Functional heterogeneity of bone morphogenetic protein receptor-II mutants found in patients with primary pulmonary hypertension. Mol Cell Biol 13: 3055-3063. doi:10.1091/mbc.E02-02-0063. PubMed: 12221115.

30. Rudarakanchana N, Flanagan JA, Chen H, Upton PD, Machado $R$ et al. (2002) Functional analysis of bone morphogenetic protein type II receptor mutations underlying primary pulmonary hypertension. Hum Mol Genet 11: 1517-1525. doi:10.1093/hmg/11.13.1517. PubMed: 12045205.

31. Beppu H, Lei H, Bloch KD, Li E (2005) Generation of a floxed allele of the mouse BMP type II receptor gene. Genesis 41: 133-137. doi 10.1002/gene.20099. PubMed: 15736264

32. Dudas M, Sridurongrit S, Nagy A, Okazaki K, Kaartinen V (2004) Craniofacial defects in mice lacking BMP type I receptor Alk2 in neural crest cells. Mech Dev 121: 173-182. doi:10.1016/j.mod.2003.12.003. PubMed: 15037318

33. Mishina Y, Hanks MC, Miura S, Tallquist MD, Behringer RR (2002) Generation of Bmpr/Alk3 conditional knockout mice. Genesis 32: 69-72. doi:10.1002/gene.10038. PubMed: 11857780. 